\title{
Size-Dependent Growth and Contact Nucleation of Calcite Crystals
}

\author{
Clifford Y. Tai, Pao-Chi Chen, and Shin-Min Shih \\ Dept. of Chemical Engineering, National Taiwan University, Taipei, Taiwan 106, R. O. C.
}

The growth kinetics and contact nucleation of calcite crystals were studied in a pH-stat crystallizer. Large seed crystals up to $230 \mu \mathrm{m}$ were successfully prepared by the gel growth technique. The crystal growth data over a wide range of crystal sizes were evaluated from titration curves by an initial slope method and then analyzed by the two-step model. The mass-transfer and surface integration rates were found to be functions of crystal size with the exception of mass-transfer rates of small crystals less than $10 \mu \mathrm{m}$. The controlling step of crystal growth process was tested using the effectiveness factor concept. Large seed crystals of calcite induced contact nucleation when a stainless-steel impeller was used for agitation. The important features of contact nucleation for calcite crystals were explored and compared with those of soluble substances.

\section{Introduction}

Crystallization and precipitation are commonly used to represent the process of generating crystals from solution for soluble and sparingly soluble substances respectively. For soluble systems, supersaturation is usually generated by cooling or evaporation and the supersaturation ranges for crystal growth, secondary nucleation and primary nucleation have been demonstrated. Thus, control of crystal-size distribution has been successful by manipulating the supersaturation level in a crystallizer, that is, supersaturation is maintained in the metastable region to eliminate primary nucleation. On the other hand, primary nucleation dominates at high supersaturation in a precipitation process for sparingly soluble substances, resulting from a rapid chemical reaction or an introduction of salting-out agents. In this case, the crystal size of the product is small and the control of crystal-size distribution is less effective (Mersmann and Kind, 1988). Another distinct feature between the two systems is on the particle morphology of the product. Single crystals are obtainable in a crystallization process of soluble substances while agglomerates of tiny crystals are formed in a precipitation process of sparingly soluble substances. It is difficult to produce large single crystals in a precipitation process.

Contact nucleation, sometimes referred to as collision breeding, appears to be the dominant mechanism of secondary nucleation in industrial crystallizers. This means that contacts between a growing crystal and walls of vessel, the stirrer or other crystals result in the formation of secondary nuclei. When agglomeration occurs in a precipitation process at high supersaturation, polycrystalline breeding, another mechanism of secondary nucleation due to breakage of a polycrystalline mass, may be significant (Strickland-Constable, 1972). Crystal growth and contact nucleation of soluble substances have been studied extensively. Important features of the system include the observation of size-dependent growth over a wide range of crystal sizes (Tai and $\mathrm{Yu}, 1989$ ), the requirement of a critical crystal size about 195-225 $\mu \mathrm{m}$ for the generation of secondary nuclei (Cayey and Estrin, 1967 and Rousseau et al., 1976) and more nuclei are produced at higher supersaturation and magma density (Garside and Shah, 1980).

Similar studies of sparingly soluble salt are limited, because large single crystals are difficult to prepare. There is one report by Etherton and Randolph (1981) on the secondary nucleation of sparingly soluble salt using well-formed seed crystals, which were separated from the feed stock used for makeup liquor in the experiment. They found that gypsum nucleates by contact mechanism when seed crystals were greater than $150 \mu \mathrm{m}$ in a mixed suspension, mixed product removal (MSMPR) crystallizer. In other studies of secondary nucleation, polycrystalline nucleation was suspected to occur, because the preparation method of well-formed seed crystal was not mentioned (Klima and Nancollas, 1987; Tsuge, Kotaki and Hibino, 1987). As far as the crystal growth of sparingly soluble salt is concerned, many reports have been published in the crystal-size range 1 to $10 \mu \mathrm{m}$ (Nielsen, 1984; Mersmann and Kind, 1988). In most 
reports, crystal growth rates of one crystal size have been measured and size-dependent growth has never been considered.

Calcium carbonate is the most widely studied system among the sparingly soluble substances because of its importance in the fields of sedimentology, oceanology, wastewater treatment, paint and paper fillers, and desalination. Calcium carbonate nucleates in two forms from aqueous solutions, that is, calcite of the hexagonal system and aragonite of the orthorhombic system, depending on the operational conditions. Usually, high supersaturation and temperature favor the formation of dendritic aragonite, which often agglomerate to form a rosette particle morphology. On the other hand, calcite nucleates in a mild environment as rhombohedron (Klein, 1985; Peters and Chang, 1987). In the study of calcite growth, experimental techniques include the MSMPR crystallizer experiment (Tsuge, Kotaki, and Hibino, 1987; Peters and Chang, 1987), the pHstat method (Giannimaras and Koutsoukos, 1987; Christoffersen and Christoffersen, 1990), the constant composition method (Meyer, 1979; Kazmlerczak, Tomson and Nancollas, 1982), the free-drift method (Reddy, 1977; House and Tutton, 1982) and the rotating disc method (Compton and Daly, 1987). The constant composition method, the pH-stat method and the MSMPR crytallizer are adequate to investigate crystal growth and contact nucleation. However, the apparatus used for the pH-stat method is less complicated.

In this study, seeded experiments were conducted in a $\mathrm{pH}$ stat apparatus to investigate the crystal growth kinetics and contact nucleation of calcite in an aqueous solution. Seed crystals were prepared by the gel growth method, which is a wellknown technique to grow high-quality single crystals at a low cost (Henisch, 1988). The growth rates of calcite crystals were evaluated from the initial slope of titration curves. The evaluation method was developed in the course of this study. Then, growth rate data were analyzed by the two-step model, which has been used by many investigators to study the growth kinetics of soluble substances (Karpinski, 1985; Tai and $\mathrm{Yu}$, 1989; Qiu and Rasmuson, 1990). After growth experiments, the Teflon impeller was replaced by a stainless-steel one to generate secondary nuclei at various operating conditions.

\section{Experimental Procedure}

\section{Crystallization system}

The experimental system for a semibath study of crystal growth and contact nucleation is shown in Figure 1. It comprises a pH-stat apparatus (Kyoto Electronic AT 200), a 1.5 $\mathrm{L}$ acrylic plastic crystallizer, a water bath and an axial-flow Teflon-made agitator. Crystal growth experiments were conducted at $30^{\circ} \mathrm{C}$ and $800 \mathrm{rpm}$. Before operation, the electrodes were standardized with buffers of $\mathrm{pH} 6.86$ and 9.18. One liter of supersaturated solution of calcium carbonate was prepared by adding sodium carbonate solution into the calcium chloride solution already in the crystallizer. Subsequently, the solution was adjusted to the desired $\mathrm{pH}$ value by adding $0.1 \mathrm{M}$ hydrochloric acid. After the pH of solution became steady, a weighted amount of calcite seeds was introduced into the crystallizer. The $\mathrm{pH}$ was maintained constant during operation, using a pH-stat apparatus to control the amount of sodium carbonate added to the crystallizer. A titration curve was obtained automatically at the end of the operation. From the titration curves, the growth rates were evaluated. Three types of solution composition (A, B, and $\mathrm{C}$ ) were investigated in the growth study. The concentration ratio, TCA/TCO, was $2.72 \mathrm{mM} /$ $0.943 \mathrm{mM}$ for type $\mathrm{A}, 2.72 \mathrm{mM} / 0.674 \mathrm{mM}$ for type $\mathrm{B}$ and $2.72 \mathrm{mM} / 0.566 \mathrm{mM}$ for type $\mathrm{C}$. The $\mathrm{pH}$ values varied from 8.1 to 9.0 . The running time was from $30 \mathrm{~min}$ to $240 \mathrm{~min}$. The operating conditions and system properties are listed in Table 1. In the nucleation study, working levels of supersaturation were higher than those in the growth study and a stainlesssteel impeller was utilized.

\section{Seed crystals}

Seed crystals of calcite used in this experiment were from

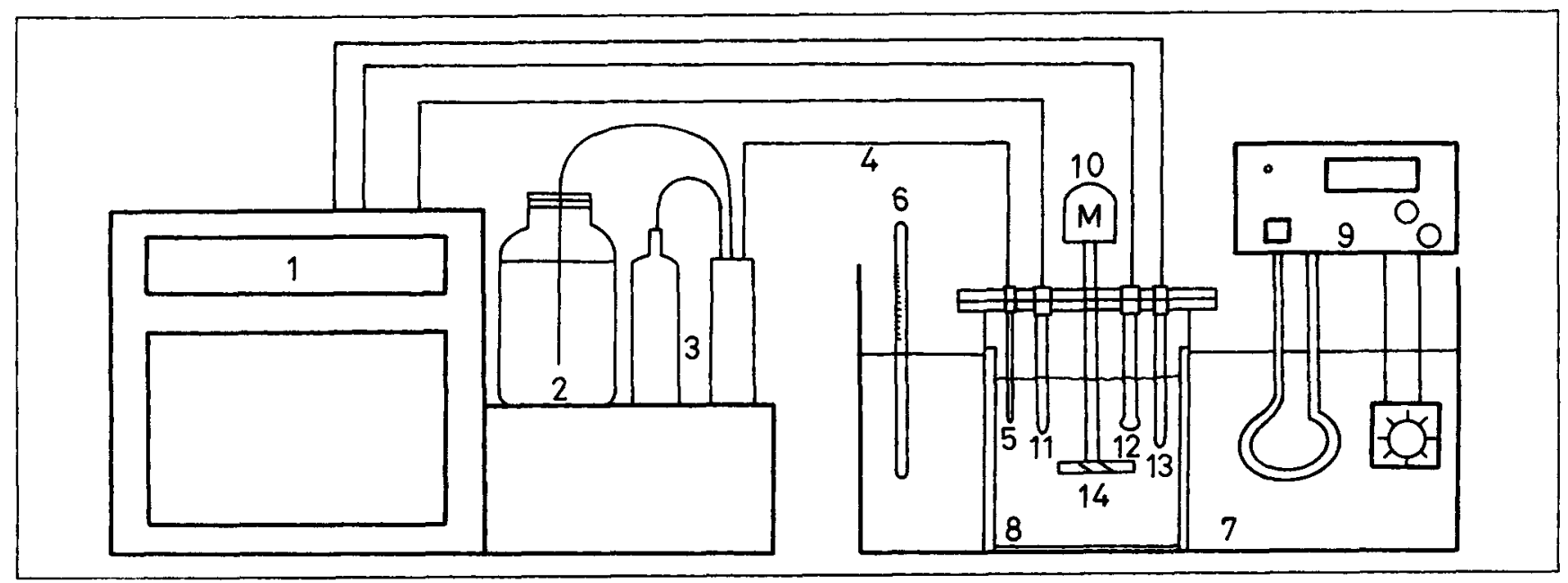

Figure 1. pH-stat crystallization system.

(1) pH and temperature indicator; (2) Reagent bottle; (3) Pumping system of reagent; (4) Reagent deliver line; (5) Burette; (6) Thermometer; (7) Water bath; (8) Crystallizer; (9) Heating system; (10) Motor; (11) Glass electrode; (12) Reference electrode; (13) Thermo-compensator; (14) Axial-flow impeller. 
Table 1. Operating Conditions and Physical Properties of the System Studied in this Experiment

\begin{tabular}{ll} 
Operating Conditions & \\
\hline working temperature, $T$ & $30^{\circ} \mathrm{C}$ \\
time of growth, $t$ & $30-240 \mathrm{~min}$ \\
speed of stirring & $800 \mathrm{rpm}$ \\
specific power input, $\epsilon$ & $0.93 \mathrm{~W} / \mathrm{kg}$ \\
pH range & $8.1-9.0$ \\
seed size & $2-230 \mu \mathrm{m}$ \\
concentration of titrant, $C_{b}$ & $4.72 \times 10^{-3}-4.72 \times 10^{-2} \mathrm{kmol} / \mathrm{m}^{3}$ \\
solution concentration & \\
$\quad$ total carbonate, TCO & $5.66 \times 10^{-4}-9.43 \times 10^{-4} \mathrm{kmol} / \mathrm{m}^{3}$ \\
$\quad$ total calcium, TCA & $2.72 \times 10^{-3} \mathrm{kmol} / \mathrm{m}^{3}$ \\
Physical Properties of Calcite & \\
\hline crystal density, $\rho_{s}$ & $2,710 \mathrm{~kg} / \mathrm{m}^{3}$ \\
ratio of surface shape factor to & \\
volume shape factor, $f_{s} / f_{v}$ & 6 \\
specific surface area, SSA & $0.00934-0.870 \mathrm{~m}^{2} / \mathrm{g}$ \\
molecular weight of calcite, $M$ & $100 \mathrm{~kg} / \mathrm{kmol}$ \\
Fluid Properties & \\
\hline solution density, $\rho$ & $-1,000 \mathrm{~kg} / \mathrm{m}^{3}$ \\
kinematic viscosity, $\nu$ & $10 \mathrm{~Pa} \cdot \mathrm{s}$
\end{tabular}

two sources: the smaller sizes less than $10 \mu \mathrm{m}$ were obtained from Nacalai Tesque Company, and the larger sizes greater than $58 \mu \mathrm{m}$ were prepared by the gel growth technique. From scanning electron microscopy (SEM) in Figure 2, the morphology of all seed crystals is rhombohedron, which is a major form of calcite confirmed by Klein et al. (1985). Crystal products from Nacalai Tesque Company were cured in a slightly supersaturated solution at $\mathrm{pH} 9.0$ for different length of time. After filtering and drying, the surface area of grown crystals was determined by the multiple-point Brunauer-Emmett-Teller (BET) technique (Micromeritics, 2100D); the values are 0.87 , 0.43 and $0.27 \mathrm{~m}^{2} / \mathrm{g}$ for different curing times. These values, along with the density of calcite $2,710 \mathrm{~kg} / \mathrm{m}^{3}$ were used to obtain the average linear dimension of a rhombohedron, approximately 2,5 and $8 \mu \mathrm{m}$, respectively. The larger seed crystals were grown in a test tube filled with silica gel. Sodium metasilicate solution was first mixed with an equal volume of ammonium carbonate solution already in a test tube. After gelation, calcium chloride solution was placed on the top of the gel. Several weeks later, calcite crystals were recovered
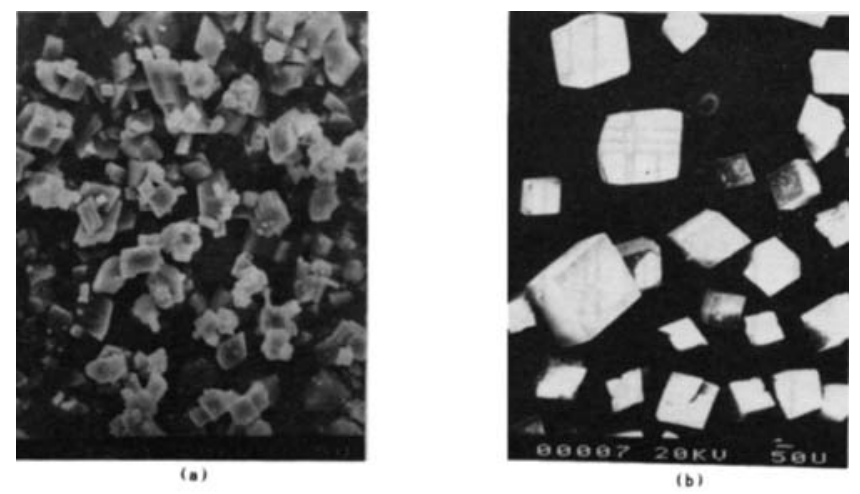

Figure 2. SEM photographs of calcite.

(a) 2- $\mu \mathrm{m}$ seed crystals; (b) large seed crystals from gel growth method. from gel and were screened by a sieve to obtain the seeds of desired sizes. Preparation procedures of silica gel and seed crystals are referred to Burta and Zemlicka (1971).

Solid composition and morphology of seed crystals prepared from the gel growth were investigated. In Figure 3a, an IR (infrared) spectra of the seed crystal is comparable with the standard spectra of calcite (Vandeberg, 1980). The patterns of $\mathrm{x}$-ray powder diffraction are shown in Figure $3 \mathrm{~b}$. The diffraction angle is in the range $15^{\circ}-60^{\circ}$ and the major absorption appears at $3.85,3.03,2.28,1.87$ and $1.60 \AA$, which are close to the values of standard card for calcite (McClune, 1983). In addition, the composition of smaller seeds obtained from the Nacalai Tesque Company were also examined by IR and Xray analyses and the results were similar to those of the seed crystals prepared by gel method.

\section{Determination of Relative Supersaturation and Crystal Growth Rate}

Supersaturation of sparingly soluble systems have different expressions in the literature. The relative supersaturation proposed by Nielsen and Toft (1984) is given by:

$$
\sigma=\left(I P^{1 / 2}-K_{\mathrm{sp}}^{1 / 2}\right) / K_{\mathrm{sp}}^{1 / 2}
$$

where $I P$ is the ionic product, defined as $I P=\mathrm{a}_{\mathrm{Ca}^{+2}} a_{\mathrm{CO}_{1}^{-2}}$ for this system, and $K_{\mathrm{sp}}$ is the solubility product.

Concentrations of ionic species, which are needed to calculate ionic activities, were computed from the experimental pH value, total calcium concentration and total carbonate concentration by successive approximation for the ionic strength (Nancollas, 1966). The computer program contains the mass action and mass balance equations and the modified Debye-Hückle equation proposed by Davies for the calculation of activity coefficient of $z_{i}$-valence ions, $y_{z i}$ (Butler, 1964). All the relevant equations are expressed below.

The mass balance equations are:

$$
\mathrm{TCA}=\left[\mathrm{Ca}^{+2}\right]+\left[\mathrm{CaCO}_{3}^{0}\right]+\left[\mathrm{CaHCO}_{3}^{+}\right]+\left[\mathrm{CaOH}^{+}\right]
$$




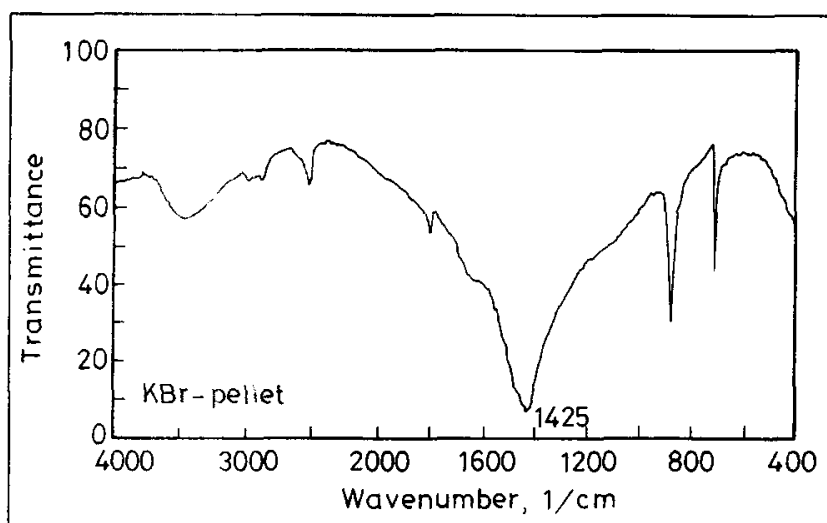

(a)

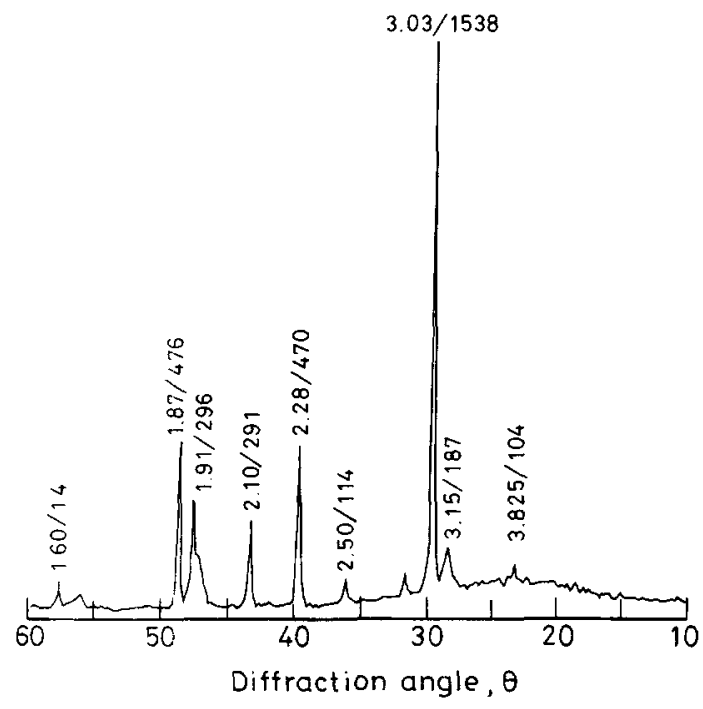

(b)

Figure 3. Spectra of calcite prepared by gel growth method.

(a) IR spectra; (b) $x$-ray powder diffraction spectra.

$$
\begin{aligned}
\mathrm{TCO}=\left[\mathrm{H}_{2} \mathrm{CO}_{3}\right]+\left[\mathrm{HCO}_{3}^{-}\right]+\left[\mathrm{CO}_{3}^{-2}\right] & \\
& +\left[\mathrm{CaCO}_{3}^{0}\right]+\left[\mathrm{CaHCO}_{3}^{+}\right]
\end{aligned}
$$

The mass action equations and $\mathrm{pK}_{i}$ values for $\mathrm{CaCl}_{2}-\mathrm{Na}_{2} \mathrm{CO}_{3}$ system at $30^{\circ} \mathrm{C}$ (Lowell, 1970) are:

$$
\begin{aligned}
\mathrm{pK}_{1} & =-\log y_{1}^{2}\left[\mathrm{H}^{+}\right]\left[\mathrm{OH}^{-}\right]=13.818 \\
\mathrm{pK}_{2} & =-\log \frac{y_{1}^{2}\left[\mathrm{H}^{+}\right]\left[\mathrm{HCO}_{3}^{-}\right]}{y_{0}\left[\mathrm{H}_{2} \mathrm{CO}_{3}\right]}=6.326 \\
\mathrm{pK}_{3} & =-\log \frac{y_{2}\left[\mathrm{H}^{+}\right]\left[\mathrm{CO}_{3}^{-2}\right]}{\left[\mathrm{HCO}_{3}^{-}\right]}=10.289 \\
\mathrm{pK}_{4} & =-\log \frac{y_{2}^{2}\left[\mathrm{Ca}^{+2}\right]\left[\mathrm{CO}_{3}^{-2}\right]}{y_{0}\left[\mathrm{CaCO}_{3}^{0}\right]}=3.226 \\
\mathrm{pK}_{5} & =-\log \frac{y_{2}\left[\mathrm{Ca}^{+2}\right]\left[\mathrm{HCO}_{3}^{-}\right]}{\left[\mathrm{CaHCO}_{3}^{+}\right]}=1.275
\end{aligned}
$$

$$
\begin{gathered}
\mathrm{pK}_{\mathrm{f}}=-\log \frac{y_{2}\left[\mathrm{Ca}^{+2}\right]\left[\mathrm{OH}^{-}\right]}{\left[\mathrm{CaOH}^{+}\right]}=1.372 \\
\mathrm{pK}_{\mathrm{sp}}=-\log y_{2}^{2}\left[\mathrm{Ca}^{+2}\right]\left[\mathrm{CO}_{3}^{-2}\right]=8.041
\end{gathered}
$$

And the modified Debye-Hückle equation is:

$$
\log \mathrm{y}_{\mathrm{zi}}=-0.509 Z_{i}^{2}\left(\frac{\sqrt{I}}{1+\sqrt{I}}-0.2 I\right)
$$

where $I$ is the ionic strength, $I=1 / 2 \sum_{i=1}^{n} Z_{i}^{2} \mathrm{C}_{\mathrm{i}}$, and $C_{i}$ includes the concentration of $\mathrm{H}^{+}, \mathrm{OH}^{-}, \mathrm{Ca}^{+2}, \mathrm{CaOH}^{+}, \mathrm{CaHCO}_{3}^{+}$, $\mathrm{HCO}_{3}^{-}, \mathrm{CO}_{3}^{-2}, \mathrm{Na}^{+}$, and $\mathrm{Cl}^{-}$.

The growth rate of calcite can be expressed as the consumption rate of TCA:

$$
\begin{aligned}
-J / v= & d(\mathrm{TCA}) / d t \\
= & d\left[\mathrm{Ca}^{+2}\right] / d t+d\left[\mathrm{CaCO}_{3}^{0}\right] / d t+ \\
& d\left[\mathrm{CaHCO}_{3}^{+}\right] / d t \\
& +d\left[\mathrm{CaOH}^{+}\right] / d t
\end{aligned}
$$

where $J$ and $v$ are molar growth rate and solution volume, respectively. Because the change of total carbonate in the crystallizer, including solution and solid phases, is equal to the consumption of total carbonate in the burette of $\mathrm{pH}$-stat apparatus, and the deposit of calcium ion on seed crystal is equal to the consumption of total calcium ion in the solution, the molar growth rate can be derived (Chen, 1992):

$$
J=f \frac{d n_{b}}{d t}=f C_{b} \frac{d V}{d t}
$$

where $f$ is a constant and is evaluated from the concentration of ion species.

Next, the molar growth rate is converted to the linear growth rate:

$$
G=\frac{f_{s}}{3 f_{\nu} \rho_{s}} \frac{M}{A} f C_{b} \frac{d V}{d t}
$$

where $f_{v}$ is the volume shape factor, $f_{s}$ the surface shape factor, $M$ the molecular weight, $A$ the total surface area of crystals, and $C_{b}$ the concentration of titrant. In Eq. 14 the total surface area, $A$, was difficult to measure during a run; only the initial surface area of seed crystals was determined. Therefore, the initial titration rate, $d V /\left.d t\right|_{t=0}$, was used to determine the growth rate of calcite in this work. The titration curves are expressed in terms of a polynomial

$$
V(t)=\sum_{i=1}^{n} a_{i} t
$$

where $a_{i}$ and $i$ are the coefficient and order of the ith term of the polynomial function. Thus, the linear crystal growth rate can be evaluated. This method is more convenient than others reported in the literature by monitoring the calcium and hy- 
drogen ion concentrations (Nancollas and Reddy, 1971) or by evaluating $d n_{b} / d t$ at other specified points (Christoffersen and Christoffersen, 1990).

\section{Results and Discussion}

\section{Crystal growth rates}

The growth rates of calcite crystals were evaluated from the titration curves, such as those shown in Figure 4. The titration volume, $V(t)$, was fitted by a high-order polynomial, then the initial slope of the curve was calculated. For example, the polynomial function of Run number B-244 in Figure 4 is:

$$
\begin{aligned}
V(t)=-0.08698+ & 0.2190 t+3.387 \times 10^{-4} \mathrm{t}^{2} \\
& -2.4856 \times 10^{-6} t^{3}+3.3203 \times 10^{-9} t^{4}
\end{aligned}
$$

and the initial titration rate is:

$$
d V(t) /\left.d t\right|_{t=0}=0.2190
$$

This value and the system constants, such as shape factors, $f$ value, crystal density and concentration of titrant tabulated somewhere else (Chen, 1992), were substituted into Eq. 14 to obtain the growth rate of various crystal sizes, ranging from 2 to $230 \mu \mathrm{m}$. These growth rates are much lower than that of soluble substances which is approximately $1.0 \times 10^{-8} \mathrm{~m} / \mathrm{s}$.

The crystal growth rates of several crystal sizes were plotted as a function of supersaturation in Figure 5. They increased with relative supersaturation and crystal size so that they were

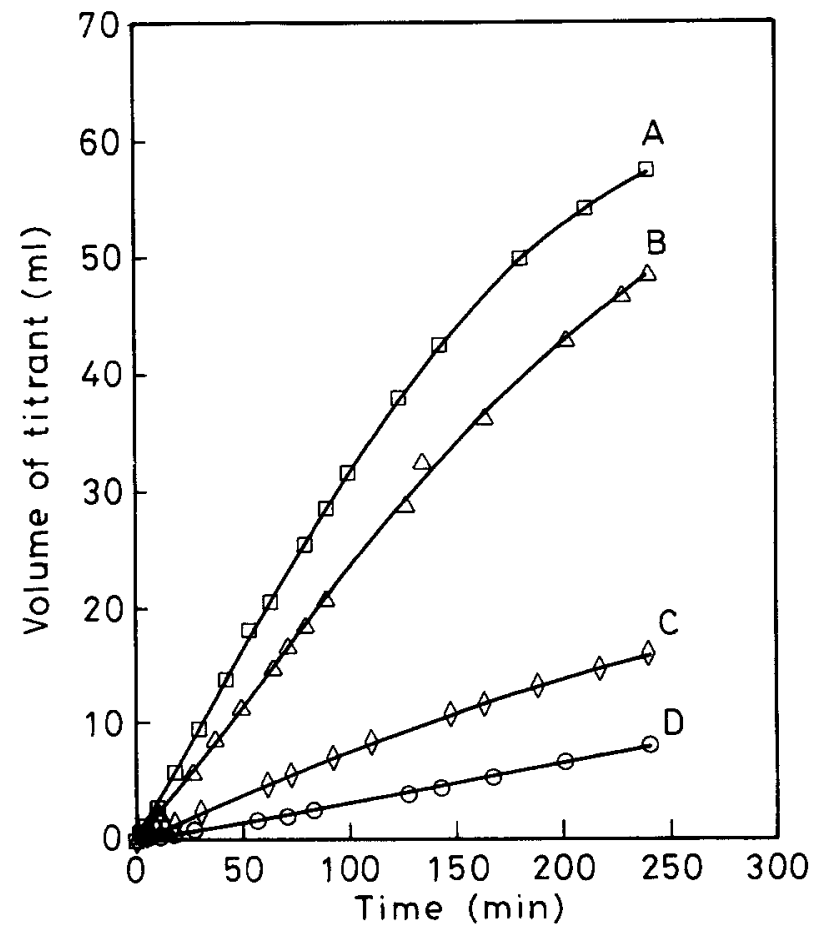

Figure 4. Typical titration curves of sodium carbonate in seeded growth experiment for $5 \boldsymbol{\mu m}$ seed.

(A) Run no. B245; (B) Run no. A244; (C) Run no. A247; (D) Run no. B248. analyzed by the two-step model expressed by functions of the two variables:

$$
\begin{aligned}
G=K_{d}\left(\sigma-\sigma_{1}\right)=K_{d o} L^{a}\left(\sigma-\sigma_{i}\right) & \text { bulk transport } \\
=K r \sigma_{i}^{r}=K_{r o} L^{b} \sigma_{i}^{r} & \text { surface integration }
\end{aligned}
$$

Combining Eqs. 18 and 19 by eliminating $\sigma_{i}$, the resultant equation is:

$$
\frac{G}{K_{d o} L^{a}}+\left(\frac{G}{K_{r o} L^{b}}\right)^{1 / r}=\sigma
$$

Using the measured growth rate and supersaturation data, we evaluated the parameters $a, b, K_{d o}$ and $K_{r o}$ for a given value of $r$. The best fit appeared at $r=2.25$, when experimental data of all crystal sizes were used in the regression analysis. The corresponding growth rates are:

$$
\begin{aligned}
G & =3.918 \times 10^{-10} L^{0.309}\left(\sigma-\sigma_{i}\right) \\
& =1.694 \times 10^{-11} L^{0.609} \sigma_{i}^{2 \cdot 25}
\end{aligned}
$$

with a regression error 0.261 , which is defined as:

$$
S_{y}=\sqrt{\frac{\left.\Sigma\left[G_{i}-G_{\mathrm{exp}, i}\right)^{2} / G_{i}^{2}\right]}{n}}
$$

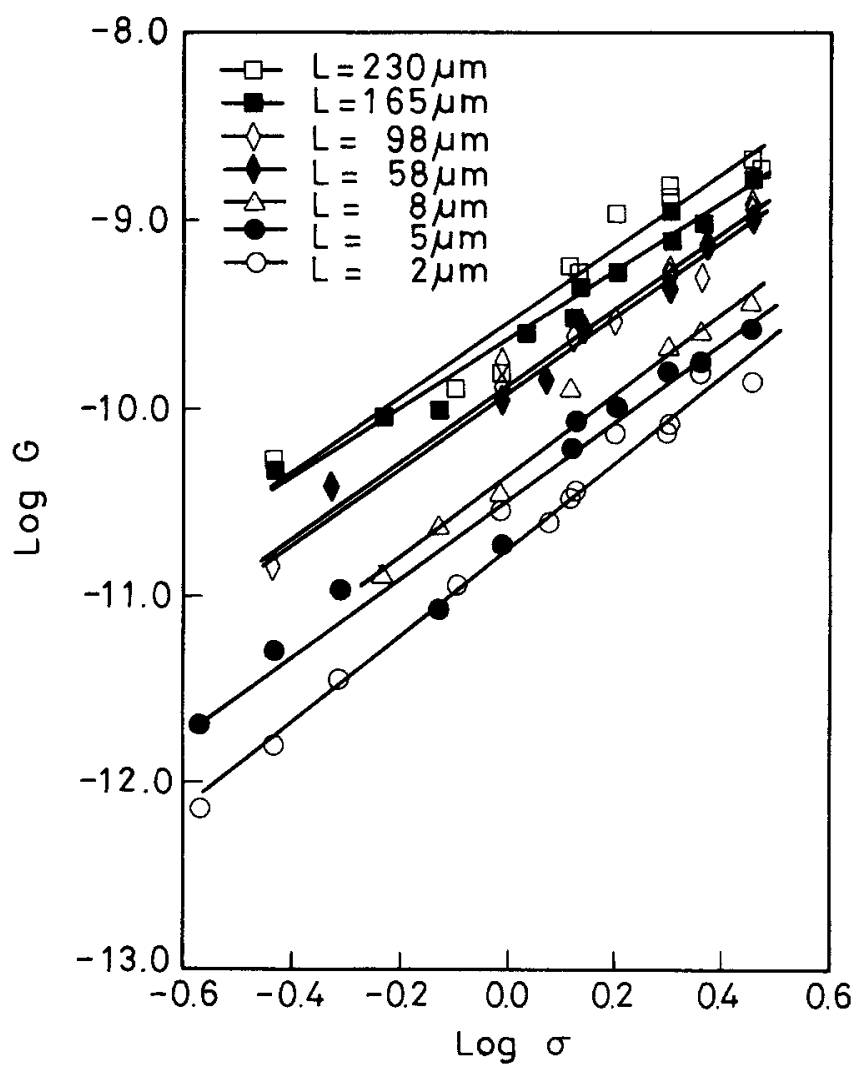

Figure 5. Overall growth rate of calcite at $30^{\circ} \mathrm{C}$ and 800 rpm.

口: $\mathrm{L}=230 \mu \mathrm{m} ; \square: \mathrm{L}=165 \mu \mathrm{m} ; \diamond: \mathrm{L}=98 \mu \mathrm{m} ; \bullet: \mathrm{L}=58 \mu \mathrm{m}$ $\Delta: \mathrm{L}=8 \mu \mathrm{m} ; \bullet: \mathrm{L}=5 \mu \mathrm{m} ; \circ: \mathrm{L}=2 \mu \mathrm{m}$. 
Suppose the growth rate of small crystals, including 2,5 and $8 \mu \mathrm{m}$, and large crystals were analyzed separately, the rate equations of the small crystals are:

$$
\begin{aligned}
G & =1.999 \times 10^{-9} L^{-0.0256}\left(\sigma-\sigma_{i}\right) \\
& =1.345 \times 10^{-11} L^{0.627} \sigma_{i}^{2 \cdot 20}
\end{aligned}
$$

with a regression error 0.231 , and the rate equations of large crystals are:

$$
\begin{aligned}
G & =5.887 \times 10^{-10} L^{0.434}\left(\sigma-\sigma_{i}\right) \\
& =1.292 \times 10^{-11} L^{0.604} \sigma_{i}^{2.02}
\end{aligned}
$$

with a regression error 0.254 .

The measured growth rates are compared with the calculated growth rates as shown in Figure 6; most data points fall within $\pm 30 \%$ of the calculated values.

It is worth noting that the difference in the surface integration rate between small and large crystals is not much, but the mass-transfer rates of them are completely different. The results suggest that the growth mechanism of the surface integration step is the same, but the mechanism of the mass transport process is different for the two size ranges. These will be discussed in detail later. So far we have attributed the variations in growth rate to size-dependent growth behavior. This apparent size-dependent growth rate may occur due to growth rate dispersion (Randolph and Larson, 1988). At the present time, we are attempting to explain the observed variations in the growth rate using a size-dependent model.

Since all the parameters of the two-step model are available, a quantitative determination of the importance of diffusion and surface integration steps can be made through the concept of effectiveness factor (Garside, 1971). The surface integration

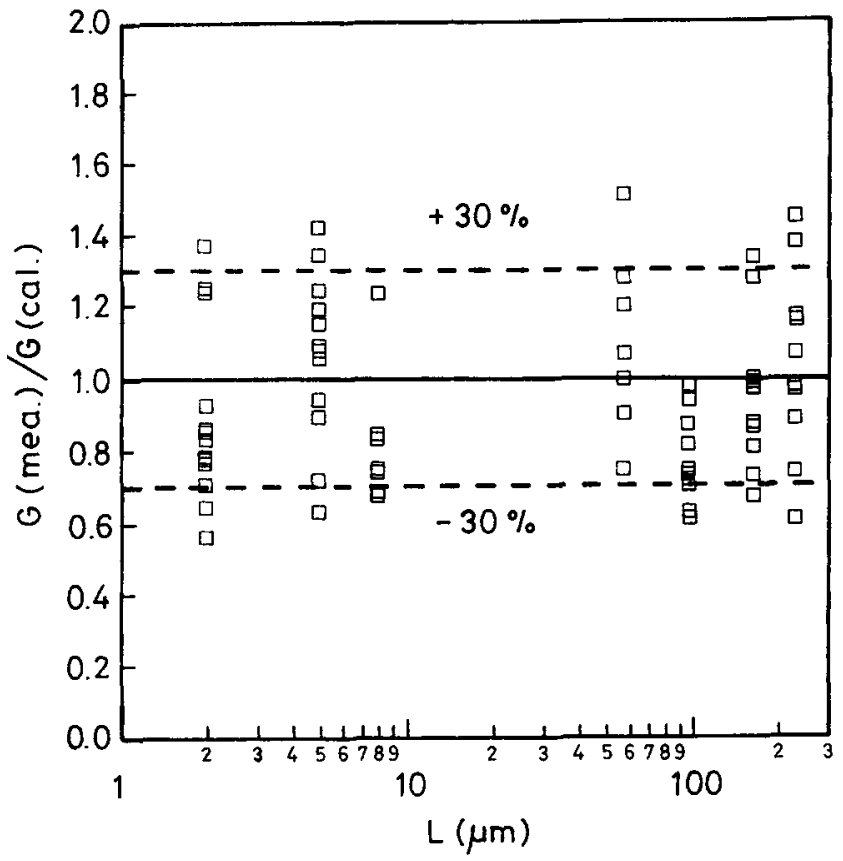

Figure 6. Comparison of measured and calculated growth rate. effectiveness factor $\eta$ for an rth-order rate is:

$$
\eta=(1-\eta D a)^{r}
$$

where $D a$ is expressed by:

$$
D a=K_{r o} L^{b-a} \sigma^{r-1} / K_{d o}
$$

Equation 29 is plotted in Figure 7; diffusion and surfaceintegration resistances are significant for large crystals and the mass-transfer resistance becomes negligible at lower supersaturation for small crystals.

\section{Comparison of growth rate of small calcite crystals}

Growth rate data of small calcite crystals $(<10 \mu \mathrm{m})$ are available in the literature. In order to compare the data from different sources, recalculation of supersaturation and correction of temperature are required. A survey of calcite growth rate is summarized in Table 2 and the rate equations are plotted in Figure 8. Driving force of crystal growth is expressed by relative supersaturation, $\sigma$, as defined in Eq. 1, and temperatures are corrected to $30^{\circ} \mathrm{C}$ by use of the activation energy found by Nancollas and Reddy (1971). The growth rates are correlated with relative supersaturation at various crystal sizes. The exponent of supersaturation varies from 2.00 to 2.41 ; our results for 2,5 and $8 \mu \mathrm{m}$ fall in between. Considering the different techniques and reactants used in the experiments to determine the growth rate, the variation is really not great. In Figure 8, growth rates from different sources show size-dependent behavior. The consistent results of this study and others in the size range 1 to $10 \mu \mathrm{m}$ were generally good, although discrepancy does exist between the 2 and $3 \mu \mathrm{m}$ crystals.

The regression results expressed as Eqs. 24 and 25 suggest that the surface integration step is responsible for size-dependent growth of small calcite crystals. The growth process of

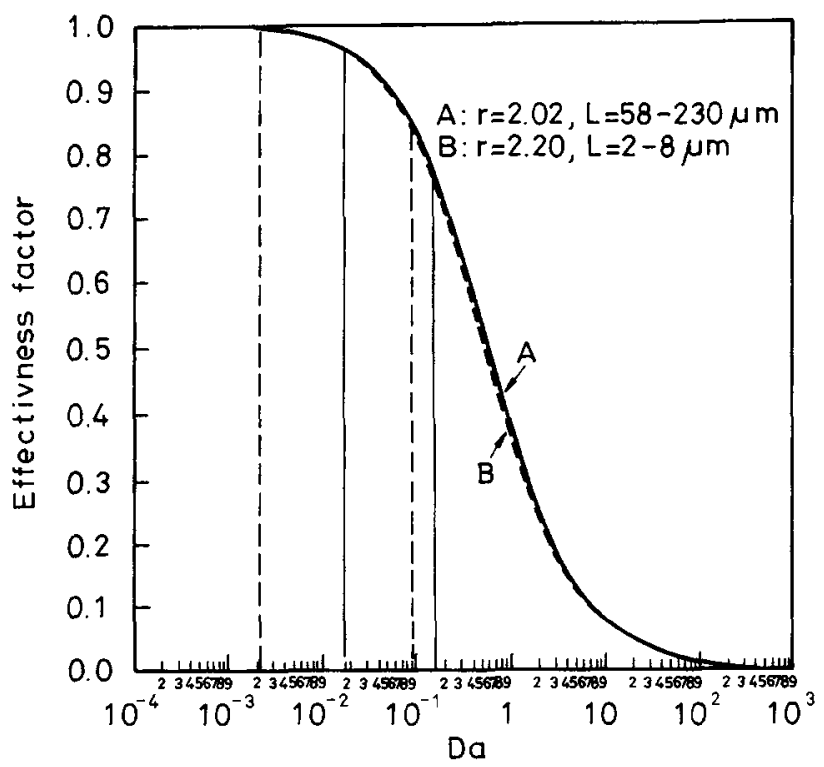

Figure 7. Operating range of Damköhler number and corresponding effectiveness factor in this experiment. 
Table 2. Growth Rate Equations of Small Calcite Crystal Reported in the Literature and this Work

\begin{tabular}{|c|c|c|c|c|c|c|}
\hline Authors & $\begin{array}{l}\text { Method } \\
\text { and } \\
\text { System }\end{array}$ & $\sigma$ & $\begin{array}{l}\text { Seed } \\
\text { Size } \\
(\mu \mathrm{m}) \\
\end{array}$ & $\begin{array}{c}\text { Agitation } \\
\text { Rate } \\
\text { (rpm) }\end{array}$ & $T\left({ }^{\circ} \mathrm{C}\right)$ & $\begin{array}{c}\text { Linear Growth } \\
\text { Rate }(\mathrm{m} / \mathrm{s}) \\
\end{array}$ \\
\hline Nancollas and Reddy (1971) & $\begin{array}{c}\text { free-drift } \\
\left(\mathrm{Na}_{2} \mathrm{CO}_{3}+\mathrm{NaHCO}_{3}+\mathrm{CaCl}_{2}\right)\end{array}$ & $0.25-1.10$ & 10 & 385 & $\begin{array}{l}25^{* *} \\
30\end{array}$ & $\begin{array}{l}G=4.52 \times 10^{-11} \sigma^{2 \cdot 19} \\
G=5.83 \times 10^{-11} \sigma^{2 \cdot 19}\end{array}$ \\
\hline $\begin{array}{l}\text { Giannimaras and } \\
\text { Koutsoukos (1987) }\end{array}$ & $\begin{array}{c}\mathrm{pH}-\mathrm{stat} \\
\left(\mathrm{NaHCO}_{3}+\mathrm{Ca}\left(\mathrm{NO}_{3}\right)_{2}\right)\end{array}$ & $0.42-1.93$ & 1 & * & $\begin{array}{l}25^{\dagger} \\
30\end{array}$ & $\begin{array}{l}G=1.02 \times 10^{-11} \sigma^{2.41} \\
G=1.32 \times 10^{-11} \sigma^{2 \cdot 41}\end{array}$ \\
\hline $\begin{array}{l}\text { Christoffersen and } \\
\text { Christoffersen (1990) }\end{array}$ & $\begin{array}{c}\mathrm{pH}-\mathrm{stat} \\
\left(\mathrm{K}_{2} \mathrm{CO}_{3}+\mathrm{KHCO}_{3}+\mathrm{Ca}\left(\mathrm{NO}_{3}\right)_{2}\right)\end{array}$ & $0.60-3.30$ & 3 & $*$ & $\begin{array}{l}37 \\
30\end{array}$ & $\begin{array}{l}G=3.00 \times 10^{-111} \sigma^{2 \cdot 00} \\
G=2.46 \times 10^{-11} \sigma^{2 \cdot 00}\end{array}$ \\
\hline
\end{tabular}

* Not reported, but agitation rate is high enough to suspend particles.

** Regression data were adopted from Run no. 21 of Nancollas and Reddy (1971).

${ }^{\dagger}$ Regression data were adopted from Table 1 of Giannimaras and Koutsoukos (1987)

calcite has been explained in terms of a spiral growth mechanism (Christoffersen and Christoffersen, 1990), yet the mechanism does not predict a size-dependent growth. A possible cause of size effect on the surface integration rate has been proposed by Garside et al. (1974) that larger crystals are likely to suffer more collisions which cause surface damage, resulting in more spiral centers and giving higher growth rate. Since the surface integration rate of calcite in the size 2-230 $\mu \mathrm{m}$ are almost identical, the difference in the number of spiral centers might be used to explain the size-dependent kinetics for the whole size range.

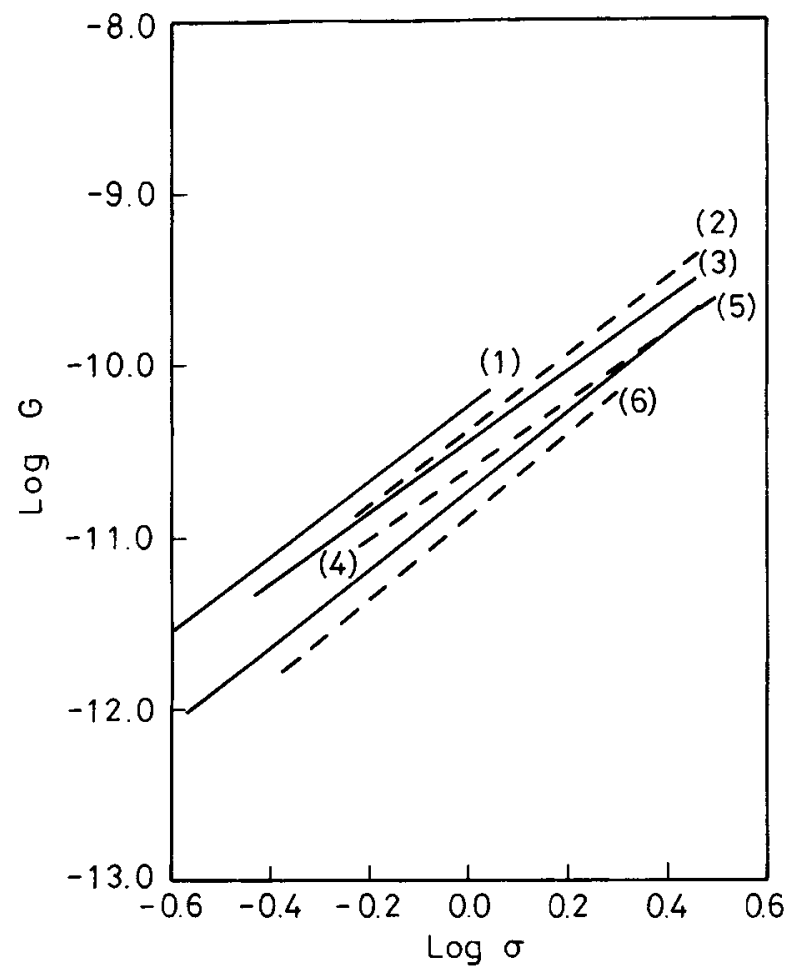

Figure 8. Growth rates of small calcite crystals.

(1): $\mathrm{L}=10 \mu \mathrm{m}$, Nancollas \& Reddy (1971); (2): $\mathrm{L}=8 \mu \mathrm{m}$, This work; (3): $\mathrm{L}=5 \mu \mathrm{m}$, This work; (4): $\mathrm{L}=3 \mu \mathrm{m}$, Christoffersen \& Christoffersen (1990); (5): $\mathrm{L}=2 \mu \mathrm{m}$, This work; (6): $\mathrm{L}=1 \mu \mathrm{m}$, Giannimaras \& Koutsoukos (1987).

\section{Crystal growth kinetics of soluble and sparingly soluble substances}

Studies on the crystal growth rate of soluble and sparingly soluble substances are numerous. In the past, large crystals have been used in the study of soluble substances. When studying sparingly soluble systems, however, small crystals have been used. Experiments of the two systems were conducted by different research groups, probably due to different experimental techniques involved. Therefore, crystal growth kinetics of soluble and sparingly soluble systems are rarely compared. Such a comparison is possible in this study because crystal growth rates of calcite in the size range 2 to $230 \mu \mathrm{m}$ were measured.

Parameters of the two-step model are presented in Table 3. The variation in parameter values can be understood because the table contains various types of crystals, including soluble inorganic, soluble organic, and sparingly-soluble inorganic. However, the kinetic behaviors of large inorganic crystals are similar, that is, mass-transfer and surface integration coefficients increase with increasing crystal size. The organic crystal (succinic acid) behaves consistently with or differently from the inorganic substances in some respects; surface integration coefficient increases with an increase in crystal size for the former, but the mass-transfer coefficient decreases with an increase in crystal size and a higher value of ' $r$ ' for the latter. Because growth rate data of organic systems other than succinic acid are not available, it is uncertain whether all organic crystals behave similarly or whether succinic acid crystal is a special case.

For small crystals, potash alum is probably the only soluble system analyzed by the two-step model for its growth kinetics (Garside and Jancic, 1976), but the kinetic parameters were not found. An increase in mass-transfer and surface integration coefficients with increasing crystal size was concluded for this soluble salt in the size range 3-70 $\mu \mathrm{m}$. Their results are consistent with ours on the surface integration coefficient, but not on the mass-transfer coefficient. The mass-transfer coefficients of small potash alum were obtained from crystal dissolution experiments by Garside and Jancic, contrasted to our experiments from crystal growth.

\section{Predicted and experimental mass-transfer coefficients}

Equations are available to predict the relationship between 
Table 3. Parameters of the Two-Step Growth Model for Calcite and Other Substances Grown in an Agitated Tank

\begin{tabular}{|c|c|c|c|c|c|c|}
\hline Authors & Systems & $\begin{array}{l}\text { Agitation } \\
\text { Speed, rpm }\end{array}$ & $\begin{array}{l}\text { Seed Size, } \\
\mu \mathrm{m}\end{array}$ & $a$ & $b$ & $r$ \\
\hline $\begin{array}{l}\text { Garside et al. } \\
\text { (1974) }\end{array}$ & $\begin{array}{l}\text { potassium } \\
\text { sulfate }\end{array}$ & $500-800$ & $570-1,180$ & 0.130 & 0.700 & 2.40 \\
\hline $\begin{array}{l}\text { Tai and Yu } \\
\text { (1989) }\end{array}$ & $\begin{array}{l}\text { potassium } \\
\text { alum }\end{array}$ & 950 & $100-700$ & 0.581 & 0.583 & 2.00 \\
\hline $\begin{array}{l}\text { Giu and Rasmuson } \\
(1990)\end{array}$ & $\begin{array}{l}\text { succinic } \\
\text { acid }\end{array}$ & $355-800$ & $400-710$ & -0.170 & 1.600 & 3.00 \\
\hline This work & calcite & 800 & $\begin{array}{l}58-230 \\
2-8\end{array}$ & $\begin{array}{c}0.434 \\
-0.0256\end{array}$ & $\begin{array}{l}0.604 \\
0.627\end{array}$ & $\begin{array}{l}2.02 \\
2.20\end{array}$ \\
\hline
\end{tabular}

- Mass-transfer coefficient, $K_{d}=K_{d o} L^{a}$ surface integration coefficient, $K_{r}=K_{r o} L^{b}$.

mass-transfer rate and crystal size. Under highly turbulent conditions at the homogeneous and isotropic state, Levich (1962) proposed the following two equations to estimate the growth rate for particle dimension that is smaller and higher than the microscale of turbulence, $\lambda_{o}$, respectively.

For small particles $\left(\mathrm{L}<<\lambda_{o}\right)$,

$$
G=K_{d o}\left(\sigma-\sigma_{i}\right)
$$

where growth rate is independent of crystal size. This result has been demonstrated for calcite, shown in Eq. 24 with a small negative exponent of crystal size and for other sparingly soluble substances in the literature (Nielson and Toft, 1984). The mass-transfer rate of potash alum crystal, which decreases with decreasing crystal size, is an exception (Garside and Jancic, 1976).

For large particles $\left(L>>\lambda_{o}\right)$,

$$
G=K_{d o} L^{1 / 3}\left(\sigma-\sigma_{i}\right)
$$

where $\lambda_{o}$ is defined as:

$$
\lambda_{o}=\left(\frac{\rho \nu^{3}}{\epsilon}\right)^{1 / 4}
$$

$\lambda_{o}$ is estimated to be $30 \mu \mathrm{m}$ in this work (Oldshue, 1983). The values of ' $a$ ' listed in Table 3 are not consistent with the value $1 / 3$ as predicted by Levich; some higher and some lower. In realizing that the assumptions of homogeneous and isotropic conditions in a crystallizer and of spherical particles are difficult to meet in a real system, the difference in the value of ' $a$ ' between systems can be understood. Yet the negative value of ' $a$ ' means that the mass-transfer coefficient decreases with increasing crystal size for succinic acid and is a rather surprising result.

\section{Contact nucleation}

In this study, a Teflon-made impeller was used for agitation in a seeded growth experiment. When it was replaced by a stainless-steel impeller, nuclei were produced. The generated crystals have the same morphology of the seed crystals, calcite, as shown in Figure 9a. They are easily distinguished from aragonite, shown in Figure $9 \mathrm{~b}$, produced by primary nucleation in an unseeded run. Therefore, experiments were designed to investigate the important features of contact nucleation found for soluble crystals, including effects of supersaturation, seed size, and seed weight. Operating conditions and experimental results are presented in Table 4 and the titration curves are shown in Figure 10.

In Figure 10, curve 1 is an unseeded run, while curves 2 and 3 are seeded runs for seed weight $80 \mathrm{mg}$ and $40 \mathrm{mg}$ respectively. The shape of curve 1 is quite different from those of curves 2 and 3 so that different nucleation mechanisms must be involved in the seeded and unseeded experiments. The abrupt increase in the consuming rate of titrant for curve 1 at 25 min indicated the initiation of spontaneous nucleation; the relative supersaturation was estimated to be 4.85 . Then, showers of nuclei and large surface area of crystals consumed titrant quickly and supersaturation became low, resulting in the negligible nucleation and growth rates. This explains the level-off of curve 1 after $80 \mathrm{~min}$. On the other hand, slopes of curves 2 and 3 increase steadily, and the experiment of curve 2 consumed more titrant than that of curve 3 , resulting from more seed crystals for curve 2 . The difference between curves 2 and 3 indicates the secondary mechanism in the production of nuclei, generating more nuclei at higher magma density.

Several important features were observed from nucleation experiments, as shown in Table 4. A threshold supersaturation, $\sigma=0.84$, and a critical crystal size, $L=165 \mu \mathrm{m}$, are required for inducing contact nucleation. Besides, more nuclei are generated at higher supersaturation and seed weight. These features have been found for soluble salts: threshold
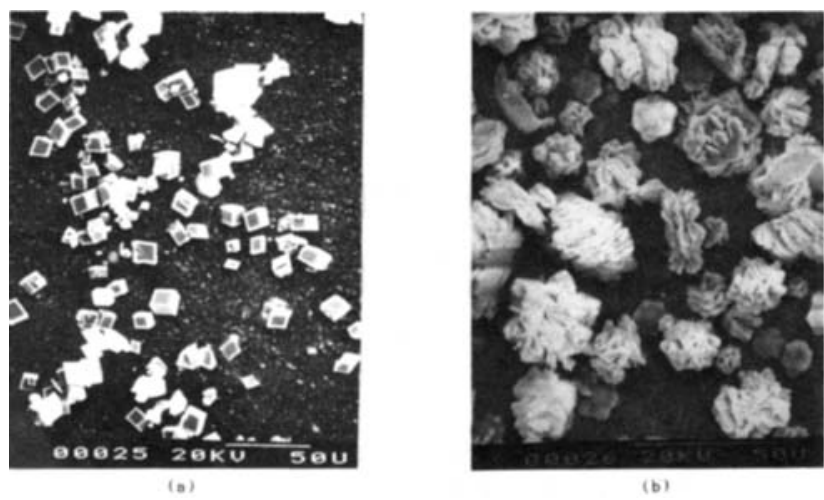

Figure 9. SEM photographs of generated calcium carbonate crystals by (a) secondary mechanism; and (b) primary mechanism. 
Table 4. Contact Nucleation Study of Calcite in an Aqueous Solution at $30^{\circ} \mathrm{C}$ and $\mathrm{pH}=9.0$

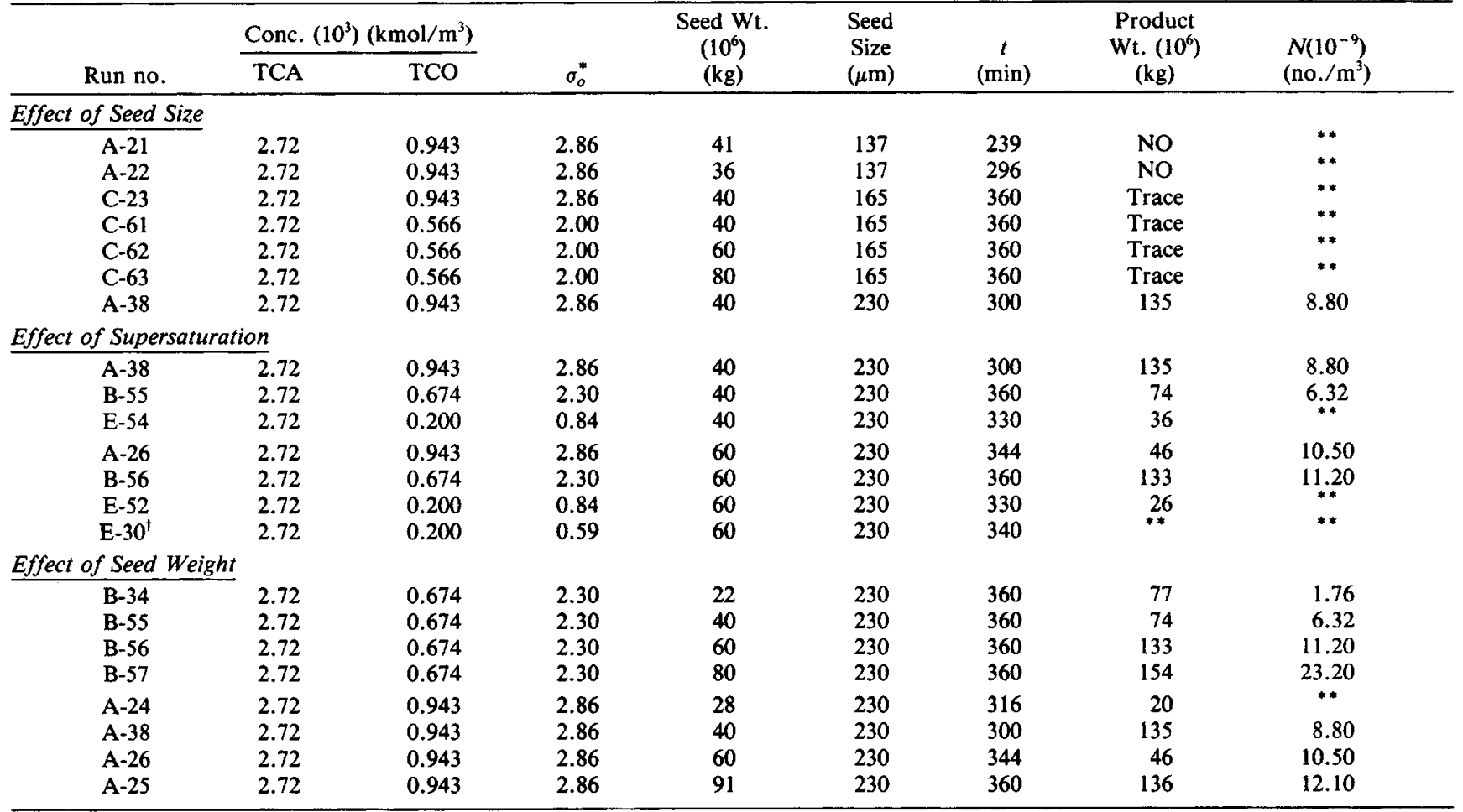

* relative supersaturation at initial stage.

** $\mathrm{N}$ cannot be determined by a particle-size analyzer.

The operating $\mathrm{pH}$ is 8.75 .

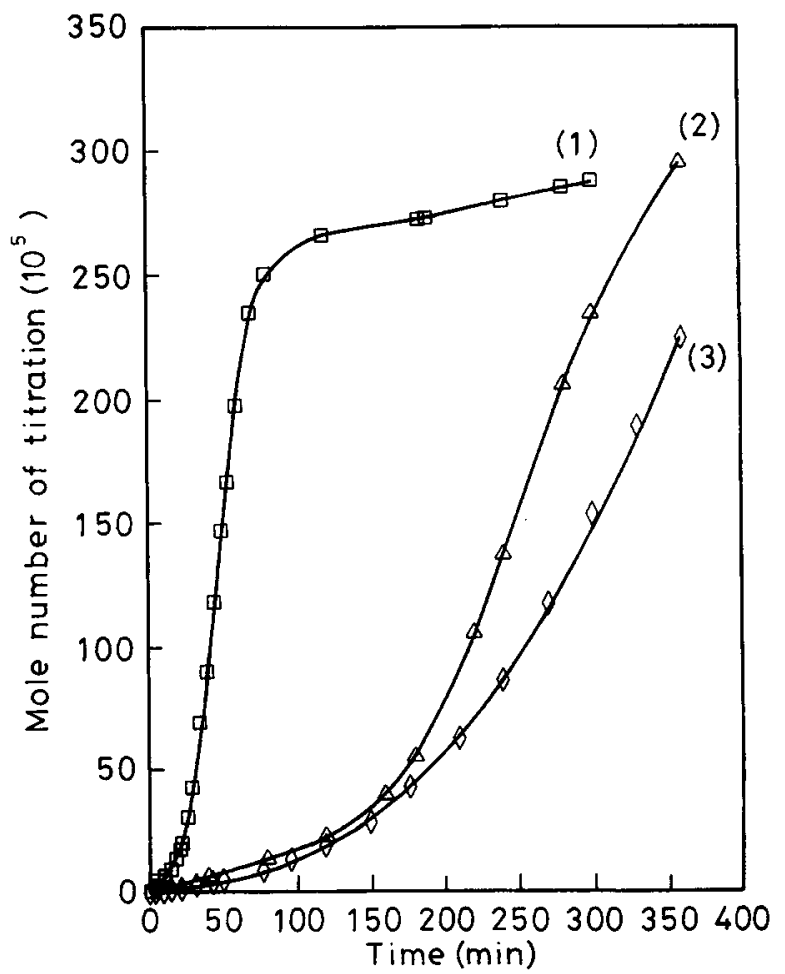

Figure 10. Titration curves of seeded and unseeded experiments for A-type solution.

(1) titration curve of unseeded experiment at $\mathrm{pH}=9.50$; (2) seeded titration curve with seed wt. $=80 \mathrm{mg}$ at $\mathrm{pH}=9.0$, Run B-57; (3) seeded titration curve with seed wt. $=40 \mathrm{mg}$ at $\mathrm{pH}=9.0$, Run B-55. supersaturation for sodium chlorate (Denk and Botsaris, 1972), critical crystal size for potassium alum (Rousseau et al., 1976; Toyokura et al., 1979), and nucleation rate increasing at higher supersaturation and magma density for several substances (Garside and Shah, 1980). The critical size for inducing contact nucleation has been found in the size range 150 to $225 \mu \mathrm{m}$ for potassium alum, magnesium sulfate, calcium sulfate and calcite. The results are quite consistent. Judging from the morphology of generated crystals, shape of titration curves, and effects of supersaturation, seed size and seed weight, we may conclude that large seed crystals of calcite, a sparingly soluble substance, would generate secondary nuclei by contact mechanism under controlled supersaturation.

\section{Conclusion}

The pH-stat apparatus is suitable for studying crystal growth kinetics and contact nucleation phenomena of sparingly soluble substances. The initial slope method developed in the course of this study is convenient to evaluate crystal growth rates. When the growth rate data of calcite crystals are analyzed by the two-step model, the mass-transfer and surface integration coefficients are found to be size-dependent, except for the mass-transfer coefficient of small crystals $(<10 \mu \mathrm{m})$. An equation can be used to express the surface integration coefficient covering the crystal size range $2-230 \mu \mathrm{m}$. The mass-transfer resistance to crystal growth becomes negligible when supersaturation and crystal size are getting smaller. The kinetic behaviors of large calcite crystal $(>58 \mu \mathrm{m})$ are similar to those of soluble inorganic crystals; mass-transfer and surface inte- 
gration resistances increase with increasing crystal size. Secondary nuclei are induced by contact mechanism when calcite crystals larger than $165 \mu \mathrm{m}$ are suspended in a supersaturated solution, using a stainless-steel impeller for agitation. More calcite nuclei are generated at higher supersaturation and magma density. Important features of contact nucleation for soluble and sparingly soluble crystals are quite similar. In this experiment, supersaturation ranges for crystal growth, secondary nucleation and primary nucleation are clearly demonstrated for the $\mathrm{CaCO}_{3}-\mathrm{H}_{2} \mathrm{O}$ system. As a result, single crystals of calcite can be produced from aqueous solutions in a pH-stat crystallizer, although the production rate will be slow.

\section{Acknowledgment}

The authors gratefully acknowledge the financial support of the National Science Council of the Republic of China through grant NSC 78-0402-E002-05.

\section{Notation}

$a=$ exponent of crystal size in Eq. 18

$a_{i}=$ polynomial coefficients in Eq. 15

$a_{\mathrm{Ca}} \cdot 2=$ activity of calcium ion

$a_{\mathrm{CO}_{3}} 2=$ activity of carbonate ion

$A=$ surface area, $\mathrm{m}^{2}$

$b=$ exponent of crystal size in Eq. 19

$C=$ concentration, $\mathrm{M}$

$C_{b}=$ concentration of titrant, $\mathrm{M}$

$D a=$ Damköhler number

$f=$ constant in Eq. 13

$f_{5}=$ surface shape factor

$f_{v}=$ volume shape factor

$G=$ linear growth rate, $\mathrm{m} / \mathrm{s}$

$G_{i}=$ calculated growth rate with Eq. $20, \mathrm{~m} / \mathrm{s}$

$G_{i, \exp }=$ measured growth rate, $\mathrm{m} / \mathrm{s}$

$I$ = ionic strength, $\mathrm{M}$

IP $=$ ionic product, $\mathrm{M}$

$J=$ consumption rate of calcium ion, $\mathrm{mol} / \mathrm{s}$

$K_{i}=$ stability constant of mass action $i, i=1 \sim 6$

$K_{d}=$ mass-transfer coefficient, defined in Eq. 18, as a function of crystal size, $\mathrm{m} / \mathrm{s}$

$K_{d t}=$ size-independent mass-transfer coefficient, defined in Eq. 18

$K_{r}=$ surface integration coefficient, defined in Eq. 19, as a function of crystal size, $\mathrm{m} / \mathrm{s}$

$K_{r 0}=$ size-independent surface integration coefficient, defined in Eq. 19

$K_{s p}=$ solubility product, $\mathrm{M}$

$L=$ crystal size, $\mu \mathrm{m}$

$M=$ molecular weight, $\mathrm{kg} / \mathrm{kmol}$

$n=$ number of data point

$n_{b}=$ mole number of titrant

$r=$ exponent of surface integration step in Eq. 19

$S_{y}=$ fitting error defined in Eq. 23

$T=$ temperature, $\mathbf{K}$

$\mathrm{TCA}=$ total calcium ion concentration, $\mathrm{M}$

$\mathrm{TCO}=$ total carbonate concentration, $\mathrm{M}$

$t=$ time, $\mathrm{s}$

$v=$ solution volume, $\mathrm{mL}$

$V=$ volume of titration, $\mathrm{mL}$

$y_{z i}=$ activity coefficient of $z_{i}$-valence species, $z_{i}=0-2$

$Z_{i}=$ valence of species $i$ in solution

\section{Greek letters}

\footnotetext{
$\epsilon=$ energy dissipation rate of turbulence, $W / \mathbf{k g}$

$\eta=$ effectiveness factor of crystal growth

$\lambda_{o}=$ microscale of turbulence, $\mu \mathrm{m}$

$\nu=$ kinematic viscosity, $\mathrm{m}^{2} / \mathrm{s}$

$\rho=$ density of fluid, $\mathrm{kg} / \mathrm{m}^{3}$
}

$\sigma=$ relative supersaturation

$\sigma_{i}=$ relative supersaturation at solid/solution interface

\section{Literature Cited}

Butler, J. N., Ionic Equilibrium, Addison-Wesley, Reading, MA (1964). Burta, C. and J. Zemlicka, "Growth of $\mathrm{CaCO}_{3}$ and $\mathrm{CaSO}_{4} \cdot 2 \mathrm{H}_{2} \mathrm{O}$," J. Crystal Growth, 10, 158 (1971).

Cayey, N. W., and J. Estrin, "Secondary Nucleation in Agitated Magnesium Sulfate Solution," Ind. Eng. Chem. Foundam., 6, 13 (1967).

Chen, Pao-Chi, "The Precipitation and Crystallization of Sparingly Soluble Salts," PhD Dissertation, National Taiwan Univ., Taipei, Taiwan (1992).

Christoffersen, J., and M. R. Christoffersen, "Kinetics of Spiral Growth of Calcite Crystals and Determination of the Absolute Rate Constant," J. Crystal Growth, 100, 203 (1990).

Compton, R. G., and P. J. Daly, "The Dissolution/Precipitation Kinetics of Calcium Carbonate: An Assessment of Various Kinetic Equations Using a Rotating Disk Method," J. Colloid Interface Sci., 115, 493 (1987).

Denk, E. G., and G. D. Botsaris, "Mechanism of Contact Nucleation," J. Crystal Growth, 13-14, 493 (1972).

Etherton, D. L., and A. D. Randolph, "Nucleation/Growth Rate Kinetics of Gypsum in Simulated FGD Liquids: Some Process Configurations for Increasing Particle Size," AIChE Symp. Ser., 77(211), p. 807 (1981).

Garside, J., "The Concept of Effectiveness Factors in Crystal Growth," Chem. Eng. Sci., 26, 1425 (1971).

Garside, J., J. W. Mullin, and S. W. Das, "Growth and Dissolution Kinetics of Potassium Sulfate Crystals in an Agitated Vessel," Ind. Eng. Chem. Fundam., 13, 299 (1974).

Garside, J., and S. J. Jancic, "Growth and Dissolution of Potash Alum Crystals in the Subsieve Size Range," AIChE J., 22, 887 (1976).

Garside, J., and M. B. Shah, "Crystallization Kinetics from MSMPR Crystallizer," Ind. Eng. Chem. Proc. Des. Dev., 19(4), 509 (1980).

Giannimaras, E. K., and P. G. Koutsoukos, "The Crystallization of Calcite in the Presence of Othophosphate," J. Colloid Interface Sci., 116(2), 423 (1987).

Henisch, H. K., "Crystals In Gel and Liesegang Rings," 2nd ed., Cambridge University Press, Cambridge (1988).

House, W. A., and J. A. Tutton, "An Investigation of the Heterogeneous Nucleation of Calcite," J. Crystal Growth, 56, 699 (1982).

Karpinski, P. H., "Importance of the Two-Step Crystal Growth Model," Chem. Eng. Sci., 40, 461 (1985).

Kazmlerczak, T. F., M. B. Tomson, and G. H. Nancollas, "Crystal Growth of Calcium Carbonate. A Controlled Composition Kinetic Study," J. Phys. Chem., 86, 103 (1982)

Klein, C., Manual of Mineralogy, 29th ed., Chapter 10, John Wiley, New York (1985).

Levich, V. G., "Physicochemical Hydrodynamics," 2nd ed., translated by Scripta Technica, Inc., Chapter 3, p. 183 (1962).

Lowell, P.S., "A Theoretical Description of the Lime Stone InjectionWet Scrubbing Process," Radian Corporation, Contract No. CPA22-69-138 (1970).

McClune, W. F., "Powder Diffraction File Search Manual Hanawalt Method Inorganic," compiled by the JCPDS, International Centre for Diffraction Data (1983).

Mersmann A., and M. Kind, "Chemical Engineering Aspects of Precipitation from Solution," Chem. Eng. Technol., 11, 264 (1988).

Meyer, H. J., "Wachstumsgeschwindigkeit Von Calcit Aus Wasserigen Losungen," J. Crystal Growth, 47, 21 (1979).

Mydlarz, J., and A. G. Jones, "Growth and Dissolution Kinetics of Potassium Sulfate Crystals in Aqueous 2-Propanol Solution," Chem. Eng. Sci., 44, 1391 (1989).

Nancollas, G. H., "Interactions in Electrolyte Solutions," Elsevier, Amsterdam (1966).

Nancollas, G. H., and M. M. Reddy, "The Crystallization of Calcium Carbonate, II. Calcite Growth Mechanism," J. Colloid and Interface Sci., 37(4), 824 (1971).

Nielsen, A. E., "Electrolyte Crystal Growth Mechanism," J. Crystal Growth, 67, 289 (1984). 
Nielsen, A. E., and J. M. Toft, "Electrolyte Crystal Growth Kinetics," J. Crystal Growth, 67, 278 (1984).

Oldshue, J. Y., Fluid Mixing Technology, Chapter 3, McGraw-Hill, New York (1983).

Peters, R. W., and Tsun-Kou Chang, "The Effect of $\mathrm{Pb}(\mathrm{II})$ as a Trace Impurity on the Crystallization Kinetics of $\mathrm{CaCO}_{3}$ Precipitation," AIChE Symp. Ser., 83(253), p. 62 (1987).

Qiu, Y., and C. Rasmuson, "Growth and Dissolution of Succinic Acid Crystals in a Batch Stirred Crystallizer," AIChE J., 36(5), 665 (1990).

Randolph, A. D., and M. A. Larson, Theory of Particulate Processes, 2nd ed., Chapter 4, Academic Press, Inc., New York (1988).

Reddy, M. M., "Crystallization of Calcium Carbonate in the Presence of Trace Concentrations of Phosphorus-Containing Anions," $J$. Crystal Growth, 41, 287 (1977).

Rousseau, R. W., K. K. Li, and W. L. McCabe, "The Influence of Crystal Size on Nucleation Rate," AIChE Symp. Ser., 72(153), p. 248 (1976).
Strickland-Constable, R. F., "The Breeding of Crystal Nuclei-A Review of the Subject," AIChE Symp. Ser., 121(68), p. 1 (1972).

Tai, C. Y., and K. H. Yu, "Growth Kinetics of Potassium Alum Crystal in a Well-Agitated Vessel," J. Crystal Growth, 96, 849 (1989).

Toyokura, K., J. Mogi, and I. Hirasawa, "Secondary Nucleation of K-Alum by Minimum Size Seeds in a Stirred Vessel," J. Chem. Eng. (Japan), 10, 35 (1977).

Tsuge, H., Y. Kotaki, and Shin-Ichi Hibino, "Reactive Crystallization of Calcium Carbonate by Liquid-Liquid Reaction," J. Chem. Eng. (Japan), 20(4), 374 (1987).

Vandeberg, J. T., An Infrared Spectroscopy ATLAS for the Coatings Industry, Federal of Societies for Coating Technology, Philadelphia (1980).

Manuscript received Oct. 5, 1992, and revision received Jan. 14, 1993. 